Pesq. Vet. Bras. 38(4):773-778, abril 2018

\title{
Estudo comparativo das diferentes técnicas empregadas na contagem diferencial de leucócitos no leite ${ }^{1}$
}

\author{
Paulo V. Takano ${ }^{2 *}$, Maiara G. Blagitz², Camila S. Mira ${ }^{3}$, Camila F. Batista ${ }^{2}$, \\ Alice M.M. Della Libera² e Fernando N. Souza ${ }^{2}$
}

\begin{abstract}
Takano P.V., Blagitz M.G., Mira C.S., Batista C.F., Della Libera A.M.M.P. \& Souza F.N. 2018. [Comparative study of distinct techniques to determine differential leukocyte counts in milk.] Estudo comparativo das diferentes técnicas empregadas na contagem diferencial de leucócitos no leite. Pesquisa Veterinária Brasileira 38(4):773-778. Departamento de Clínica Médica, Faculdade de Medicina Veterinária e Zootecnia, Universidade de São Paulo, Avenida Prof. Dr. Orlando Marques de Paiva 87, Cidade Universitária, São Paulo, SP 05508-270, Brazil. E-mail: paulo.takano@usp.br

Milk somatic cell count (SCC) is the basis of mastitis and milk quality control programs, however it not differentiate the distinct leukocyte populations which in turn can improve the diagnosis of mastitis. Thus, the present study aimed to evaluate different techniques used to measure the distinct leukocyte populations in milk in attempt to improve the diagnosis of mastitis. Here, milk samples from 31 dairy cows (124 quarter milk samples) were used. The differential leukocytes count was determined by cytocentrifugation, direct microscopy smears, and monoclonal antibodies by flow cytometry. The automatic SCC was also performed. The results showed a positive and significant correlation between the proportion of polymorphonuclear leukocytes determined by all techniques and automatic cell count; although a discrete higher correlation between flow cytometry and automatic SCC was found. Furthermore, the present study reinforces the idea that macrophages were the predominant cell type in mammary gland with low SCC. The proportion of each leukocyte population differ among techniques, probably due to the subjectivity of the examiner in the evaluation of the differential leukocyte counts by cytocentrifugation and direct microscopy smears, which emphasize that flow cytometry can be a useful and feasible tool in the diagnosis and control of mastitis.
\end{abstract}

INDEX TERMS: Comparative study, leukocytes, milk, intramammary infection, flow cytometry, mastitis, diagnosis, somatic cell count, clinical analysis.

RESUMO.- A contagem de células somáticas (CCS) é um parâmetro amplamente utilizado para monitorar a saúde do úbere e a qualidade do leite, porém não diferencia as distintas populações leucocitárias. Portanto, a diferenciação das populações celulares no leite pode aprimorar o diagnóstico da

\footnotetext{
${ }^{1}$ Recebido em 25 de maio de 2017.

Aceito para publicação em 11 de junho de 2017.

Parte da Tese da terceira autora apresentado ao Programa de PósGraduação em Ciências, Faculdade de Medicina Veterinária e Zootecnia, Universidade de São Paulo.

${ }^{2}$ Departamento de Clínica Médica, Faculdade de Medicina Veterinária e Zootecnia, Universidade de São Paulo (USP), Avenida Prof. Dr. Orlando Marques de Paiva 87, Cidade Universitária, São Paulo, SP 05508-270, Brasil. *Autor para correspondência: paulo.takano@usp.br

${ }^{3}$ Universidade Federal do Paraná, Setor Palotina, Rua Pioneiro 2153, Jardim Dallas, Palotina, PR 85950-000, Brasil.
}

mastite bovina. Dessa forma, o objetivo do presente trabalho foi avaliar as diferentes técnicas de contagem diferencial de leucócitos no leite para diagnosticar precisamente a mastite. Para tal, foram utilizadas 31 vacas da raça holandesa preta e branca em lactação (124 quartos mamários). Foram empregadas a contagem automática de células somáticas, e a contagem diferencial de leucócitos pelas técnicas de citocentrifugação, contagem diferencial de leucócitos por esfregaço direto, e citometria de fluxo com a utilização de anticorpos monoclonais específicos para identificação de cada população leucocitária. Os resultados demonstraram correlação positiva e significativa entre a proporção de leucócitos polimorfonucleares pelas diferentes técnicas e a contagem automática de células somáticas, sendo observada uma correlação discretamente mais forte com a citometria de fluxo. Além disso, foi demonstrado 
que os macrófagos são a população predominante no leite oriundo de glândula mamária com baixa CCS. Observaram-se também diferenças na proporção das distintas populações leucocitárias entre as distintas técnicas, resultado da possível subjetividade do examinador na contagem diferencial de leucócitos pelas técnicas de citocentrifugação e contagem microscópica direta por esfregaços, o que reforça que a citometria de fluxo pode ser uma ferramenta confiável no controle e diagnóstico da mastite.

TERMOS DE INDEXAÇÃO: Estudo comparativo, contagem diferencial, leucócitos, leite, infecção intramamária, citometria de fluxo, mastite, diagnóstico, contagem de células somáticas, análise clínica.

\section{INTRODUCÃ̃}

Mastite é o processo inflamatório da glândula mamária responsável por grandes perdas para o produtor, seja pelo descarte de leite, uso de antimicrobianos, maior demanda de mão de obra e redução na produção e qualidade do leite (Hogeveen et al. 2011). Como ferramenta para diagnosticar a afecção em questão, a International Dairy Federation (IDF 1971) propôs a adoção da contagem de células somáticas (CCS) para analisar se o úbere está sadio ou não, assim como a qualidade do leite.

A CCS é economicamente viável e apresenta a capacidade de mensurar inúmeras variedades celulares, entretanto não distingue as distintas populações celulares (Koess \& Hamann 2008). É definido que geralmente a celularidade no leite acima de 200.000 de células/mL, o quarto mamário é considerado infectado (Schukken et al. 2003, Della Libera et al. 2011). Porém esse limiar é tênue, pois logo no início do processo infeccioso, a contagem de células somáticas pode apresentar valores abaixo desse limiar (Koess \& Hamann 2008, Mira et al. 2013). Por outro lado, o aumento discreto da celularidade do leite, abaixo de 200.000 células/mL, é geralmente observado nas infecções intramamárias (IMI) por agentes patogênicos secundários, como Corynebacterium bovis e estafilococos coagulase-negativos (Schukken et al. 2009, Souza et al. 2016). Há ainda casos de IMI por patógenos com perfil cíclico de eliminação e, consequentemente, são acompanhados com variações na celularidade do leite, como já descrito nas IMI por Staphylococcus aureus (Walker et al. 2011).

Assim, pelo supracitado, fica claro que a baixa CCS pode ocorrer em quartos mamários sadios e infectados e, portanto, pode comprometer o controle da mastite. Em glândulas sadias, por exemplo, é constatado predomínio de leucócitos mononucleares (MN). Em contrapartida, quando infectada a população de leucócitos polimorfonucleares (PMN) aumenta drasticamente, predominando os neutrófilos (Sarikaya et al. 2005, Souza et al. 2012). Os PMN compõem a fração granulócita e são assim chamados devido à variabilidade de lóbulos nucleares quando na forma adulta e são compostas pelos: eosinófilos, basófilos e neutrófilos. Já os MN, não apresentam essa lobulação durante a maturação na medula permanecendo com a estrutura nuclear esférica ou com diminutas reentrâncias. Aqueles que compõem essa classe são os linfócitos e monócitos, este último em particular apresenta grande importância na imunidade do animal por se diferenciar em macrófagos. Estes são tidos como fagócitos e são responsáveis por, além de fagocitar debris, partículas inertes e microrganismos, estimular o sistema imune com sua produção e secreção de moléculas citocinas (Abbas et al. 2012).

Portanto, considerando o aumento na proporção de neutrófilos durante o processo infeccioso (Souza et al. 2012), a diferenciação das populações celulares presente no leite pode aprimorar o diagnóstico da mastite bovina. A contagem microscópica direta por esfregaços é rotineiramente utilizada para diferenciação das populações celulares, no entanto, demanda maior tempo para análise e apresenta baixa repetibilidade devido à subjetividade da avaliação (Koess \& Hamann 2008). Por outro lado, a citometria de fluxo apresenta maior rapidez e sua reprodutibilidade é alta em comparação a técnica de contagem microscópica direta por esfregaços e pela técnica de citocentrifugação, avaliando mais de 10.000 células em um curto espaço de tempo (Koess \& Hamann 2008).

Trabalhos empregando a citometria de fluxo (Rivas et al. 2001, Koess \& Hamann 2008, Schwarz et al. 2011, Pilla et al. 2013, Blagitz et al. 2015), citocentrifugação (Dulin et al. 1982, Mira et al. 2013) e contagem microscópica direta por esfregaços (Dosogne et al. 2003, Pilla et al. 2013) já foram realizados. Portanto, o trabalho em questão apresenta suma importância para a comunidade científica uma vez que até o momento, até onde se sabe, não há relatos de trabalhos que avaliem as três técnicas de contagem de células somáticas e sua respectiva relação com o diagnóstico microbiológico.

Desta forma, o presente estudo teve como objetivo avaliar a proporção de leucócitos polimorfonucleares e mononucleares em glândulas mamárias com distintas celularidades no leite determinada pelas técnicas de contagem diferencial de leucócitos e citometria de fluxo.

\section{MATERIAL E MÉTODOS}

Animais e colheita de leite. Foram utilizadas 31 vacas da raça holandesa preta e branca em lactação (124 quartos mamários). As amostras de leite da cisterna da glândula mamária (Sarikaya et al. 2005) foram coletadas, logo após o descarte dos três primeiros jatos, para contagem automática de células somáticas e determinação da proporção das populações leucocitárias pelas diferentes técnicas.

Contagem automática de células somáticas. As amostras de leite encaminhadas para a CCS automática foram colhidas em frascos, com capacidade de $40 \mathrm{~mL}$, contendo como conservante o bronopol. A CCS automática foi avaliada por citometria de fluxo utilizando-se o equipamento Somacount 300 (Bentley Instruments, Chaska, EUA).

CCS microscópica. As amostras de leite destinadas à CCS microscópica direta por esfregaços foram avaliadas de acordo com o método de Prescott \& Breed (1910) e modificado por Blagitz et al. (2013a). As lâminas foram confeccionadas em duplicatas. Após secas e fixadas em metanol, foram coradas pelo corante de Rosenfeld. Os esfregaços de leite corados foram examinados em microscopia de campo claro, com magnitude de 100X. Os leucócitos foram diferenciados em MN e PMN.

Contagem de células somática diferencial por citocentrifugação. As amostras de leite destinadas a CCS diferencial por citocentrifugação foram preparadas de acordo com a técnica descrita por Della Libera et al. (2004). As amostras de leite foram colhidas em frascos cônicos com capacidade de $50 \mathrm{~mL}$. Aproximadamente $25 \mathrm{~mL}$ de leite foram colhidos com $25 \mathrm{~mL}$ de PBS. Estas amostras foram centrifugadas a $450 \mathrm{xg}$ por 20 minutos à $4^{\circ} \mathrm{C}$ e o sobrenadante foi desprezado. 0 botão celular decantado no fundo do frasco foi desprendido por aspersão $5 \mathrm{~mL}$ de PBS e repetido o procedimento de centrifugação. Novamente o sobrenadante foi desprezado e o botão celular suspendido com 
$1 \mathrm{~mL}$ de RPMI 1640. Alíquotas de $200 \mu \mathrm{L}$ da suspensão celular do leite foram submetidas à citocentrifugação (Cytospin 3 SHANDON ${ }^{\circledR}$, Minnesota, EUA) a uma força centrífuga real (FCR) de 28xg por seis minutos. A partir do sedimento foram confeccionadas lâminas em triplicatas, coradas pelo método de Rosenfeld, contadas e diferenciadas 400 células em microscopia de campo claro, com aumento de $100 \mathrm{X}$ observando-se os diferentes tipos celulares.

Citometria de fluxo. Para determinação da proporção das diferentes populações leucocitárias por citometria de fluxo, inicialmente realizou-se o isolamento celular das amostras de leite, e então se utilizou anticorpos monoclonais para identificação das populações de neutrófilos, monócitos/macrófagos e linfócitos utilizando anticorpos monoclonais, conforme descrito abaixo.

Para o isolamento das células do leite foram coletados aproximadamente $500 \mathrm{~mL}$ de leite por quarto mamário em frascos com capacidade para $1 \mathrm{~L}$. Em cada frasco, foram colocados $500 \mathrm{~mL}$ de solução salina tamponada (PBS) e 500mL de leite. Estas foram mantidas e encaminhadas ao laboratório sob-refrigeração. As amostras foram centrifugadas a $1.000 \mathrm{xg}$ por 15 minutos $\left(4^{\circ} \mathrm{C}\right)$, conforme as orientações de Blagitz et al. (2013b). Após a centrifugação, o sobrenadante foi desprezado pela inversão única do frasco. 0 botão celular, conservado na superfície inferior do frasco, foi removido por meio de aspersão gentil de aproximadamente $30 \mathrm{~mL}$ de PBS e transferido para frascos de $50 \mathrm{~mL}$. Em seguida, estas amostras foram centrifugadas a $400 \mathrm{xg}$ por 10 minutos $\left(4^{\circ} \mathrm{C}\right)$. Depois de desprezado o sobrenadante, o botão celular formado foi ressuspendido em aproximadamente $10 \mathrm{~mL}$ de PBS. As amostras de cada quarto mamário foram unidas em um único frasco de $50 \mathrm{~mL}$. Este foi novamente centrifugado a $400 \mathrm{xg}$ por 10 minutos a $4^{\circ} \mathrm{C}$. Após desprezar o sobrenadante, as células foram ressuspendidas em $1 \mathrm{~mL}$ de meio de cultivo celular Roswell Park Memorial Institute (RPMI 1640; nº cat. R7638, Sigma Aldrich, St. Louis, EUA) enriquecido com soro fetal bovino a $10 \%$. Posteriormente, realizou-se contagem de células em câmara de Neubauer e a viabilidade celular foi avaliada por meio da exclusão do azul de Trypan. Em seguida, a suspensão celular foi ajustada em $2 \times 10^{6}$ células viáveis $/ \mathrm{mL}$.

Para a quantificação das populações de leucócitos lácteos, as amostras de leite foram avaliadas por citometria de fluxo (FACSCalibur ${ }^{T M}$ Becton Dickinson Immunocytometry System ${ }^{T M}$, San Diego, EUA) quanto às porcentagens das distintas populações leucocitárias, conforme previamente descrito por Blagitz et al. (2015). Apesar do anticorpo monoclonal CD14 ser utilizado para identificar os macrófagos e monócitos, os neutrófilos podem expressar CD14 no leite (Blagitz et al. 2015). Assim, os macrófagos e monócitos no leite foram identificados baseados na utilização dos anticorpos monoclonais CD14 e CH138, sendo positivo para CD14, e negativo para CH138. Portanto, para identificar macrófagos foi utilizado o anticorpo monoclonal mouse IgG1 anti-bovine CD14 (no cat. MM61A, VMRD Pullman, Pullman, EUA) e o anticorpo monoclonal secundário goat anti-mouse IgG1 conjugado ao aloficocianina (APC; no cat. A10541, Invitrogen, Carlsbad, EUA). Para a identificação dos polimorfonucleares $\left(\mathrm{CH} 138^{+}\right)$do leite foi utilizado o anticorpo monoclonal mouse IgM anti-bovine CH138A (no cat. CH138A, VMRD Pullman, Pullman, EUA) e o anticorpo monoclonal secundário goat anti-mouse IgM conjugado ao fluorocromo ficoeritrina (PE; $\mathrm{n}$ o cat.M31504, Invitrogen, Carlsbad, EUA). Em outra alíquota, a população de linfócitos foi identificada pelas populações de linfócitos T (CD3 ${ }^{+}$e B (CD21 $\left.{ }^{+}\right)$ utilizando anticorpos monoclonais específicos. Para a identificação da população de linfócitos T foi utilizado o anticorpo monoclonal mouse anti-bovine CD3 (no cat. MM1A, VMRD Pullman, EUA) e o anticorpo monoclonal secundário goat anti-mouse IgG1 conjugado ao fluorocromo ficoeritrina-Cy5 (PE-Cy5; cat. no M32018, Invitrogen, Carlsbad,
EUA). Para a identificação da população de linfócitos B foi utilizado o anticorpo monoclonal mouse anti-bovine CD21 (no cat. BAQ15A, VMRD Pullman, Pullman, EUA) e o anticorpo monoclonal secundário goat anti-mouse IgGM conjugado ao fluorocromo isotiocianato de fluoresceína (FITC; cat. no M31501, Invitrogen, Carlsbad, EUA).

Inicialmente, foram adicionados $100 \mu \mathrm{L}$ da suspensão celular juntamente com $1.000 \mu \mathrm{L}$ de PBS e centrifugadas a $250 \mathrm{xg}$ por 8 minutos. Após desprezar o sobrenadante, o botão celular foi ressuspendido em $100 \mu \mathrm{L}$ de PBS e foi adicionado $1 \mu \mathrm{L}$ do respectivo anticorpo primário, e incubado por 30 minutos em temperatura ambiente. Ao final dos 30 minutos foram adicionados $1.000 \mu \mathrm{L}$ de PBS e realizada nova centrifugação. Seguida de ressuspensão em $100 \mu \mathrm{L}$ de PBS com $1 \mu \mathrm{L}$ do respectivo anticorpo secundário. Incubou-se por 30 minutos à temperatura ambiente sob a ausência da luminosidade, para então adicionar $1.000 \mu \mathrm{L}$ de PBS em cada tubo e submetê-los a centrifugação em $250 x g$ por 8 minutos. Ao final, foram adicionados $300 \mu \mathrm{L}$ de PBS com albumina sérica bovina a 0,1\% (Inlab, São Paulo, Brasil). Foram adquiridos aproximadamente dez mil eventos. Os dados obtidos nas leituras da citometria de fluxo foram analisados em software próprio (FlowJoTreestar - Versão 7.6.1 para Windows, Ashland, EUA).

Análise estatística. A normalidade dos dados foi inicialmente verificada pelo teste de kolmogorov-Smirnov. A porcentagem de linfócitos por citometria de fluxo foi determinada pela soma da porcentagem de linfócitos $\mathrm{B}$ e linfócitos T. Para os dados com distribuição não paramétrica, utilizou-se o teste de Friedman para as comparações entre a porcentagem de PMN e MN pelas diferentes técnicas (citometria de fluxo, citocentrifugação e contagem microscópica direta por esfregaços). Para os dados com distribuição paramétrica, utilizou-se o teste Repeated Measures of ANOVA para as comparações entre a porcentagem de PMN e MN pelas distintas técnicas (citometria de fluxo, citocentrifugação e contagem microscópica direta por esfregaços). Para os dados com distribuição não paramétrica, as comparações entre a porcentagem de linfócitos e macrófagos pela citometria de fluxo e citocentrifugação foram analisadas pelo teste de Wilcoxon. Para os dados com distribuição paramétrica, as comparações entre a porcentagem de linfócitos e macrófagos pela citometria de fluxo e citocentrifugação foram analisadas pelo teste T Student para amostras pareadas. A correlação entre as variáveis foram realizadas pela correlação de Spearman (dados não paramétricos) e correlação de Pearson (dados paramétricos; Sampaio 2010).

\section{RESULTADOS}

Os resultados do presente estão sumarizados nos Quadros 1 e 2 . Observou-se que conforme a CCS aumentava, a porcentagem de PMN também aumentava independentemente da técnica. Assim, caracterizando uma correlação positiva e significativa entre elas. No entanto, a porcentagem de neutrófilos pela técnica de citocentrifugação foi maior que as demais técnicas, independente da faixa de CCS. E, a citometria de fluxo apresentou o valor " $r$ " um discretamente maior quando comparado com as outras técnicas de contagem diferencial de leucócitos.

Por outro lado, quando as técnicas foram comparadas em relação à proporção de $\mathrm{MN}$, a correlação foi negativa e significativa com a CCS automática, sendo que as técnicas corroboram entre elas. No entanto, a porcentagem de $\mathrm{MN}$ foi geralmente maior na contagem microscópica direta por esfregaços

A correlação da porcentagem de macrófagos pela técnica de citocentrifugação com a CCS apresentou-se negativa 
Quadro 1. Correlação entre as porcentagens de leucócitos polimorfonucleares, leucócitos mononucleares, macrófagos e linfócitos entre as técnicas de contagem microscópica diferencial de leucócitos por esfregaço direto, citocentrifugação, citometria de fluxo e a contagem automática de células somáticas

\begin{tabular}{|c|c|c|c|c|}
\hline \multicolumn{5}{|c|}{ Leucócitos polimorfonucleares } \\
\hline & Microscópica & Citocentrifugação & Citometria & CCS \\
\hline Microscópica & 1,00 & $0,45^{*}$ & $0,54^{*}$ & $0,39 *$ \\
\hline Citocentrifugação & & 1,00 & $0,50 *$ & $0,43^{*}$ \\
\hline Citometria & & & 1,00 & $0,48^{*}$ \\
\hline CCS & & & & 1,00 \\
\hline \multicolumn{5}{|c|}{ Leucócitos mononucleares } \\
\hline & Microscópica & Citocentrifugação & Citometria & CCS \\
\hline Microscópica & 1,00 & $0,42^{*}$ & $0,42 *$ & $-0,39 * *$ \\
\hline Citocentrifugação & & 1,00 & $0,29 * * *$ & $-0,30 * * *$ \\
\hline Citometria & & & 1,00 & $-0,30 * * *$ \\
\hline CCS & & & & 1,00 \\
\hline \multicolumn{5}{|c|}{ Macrófagos } \\
\hline & Citocentrifugação & Citometria & CCS & \\
\hline Citocentrifugação & 1,00 & $0,18^{* * * *}$ & $-0,11^{\mathrm{ns}}$ & \\
\hline Citometria & & 1,00 & $-0,65^{*}$ & \\
\hline CCS & & & 1,00 & \\
\hline \multicolumn{5}{|c|}{ Linfócitos } \\
\hline & Citocentrifugação & Citometria & CCS & \\
\hline Citocentrifugação & 1,00 & $-0,30 * * *$ & $-0,35^{* *}$ & \\
\hline Citometria & & 1,00 & $0,40^{* *}$ & \\
\hline CCS & & & 1,00 & \\
\hline
\end{tabular}

Quadro 2. Porcentagem de leucócitos polimorfonucleares, leucócitos mononucleares, macrófagos e linfócitos no leite de vacas Holandesas em lactação pelas técnicas de contagem microscópica diferencial de leucócitos por esfregaço direto, citocentrifugação e citometria de fluxo

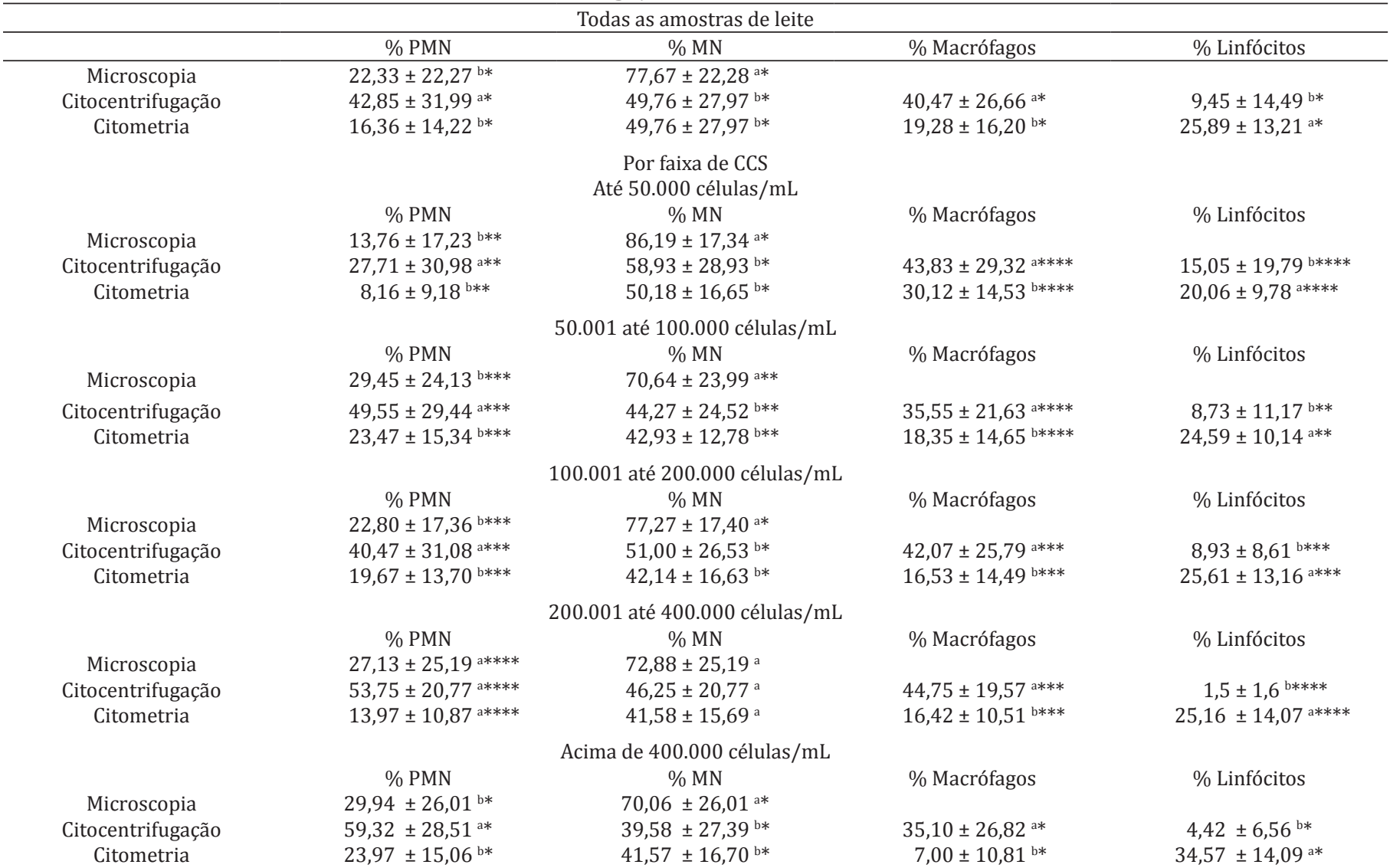
${ }^{*} P<0,0001,{ }^{* *} P<0,001,{ }^{* * *} P<0,01,{ }^{* * * *} P<0,05 ;$ PMN = leucócitos polimorfonucleares, MN= leucócitos mononucleares, CCS = contagem automática de células somáticas. 
e não significativa enquanto que a citometria de fluxo foi negativa e significativa. Já a porcentagem de macrófagos na citocentrifugação apresentou-se maior em relação à citometria de fluxo independente da faixa de CCS.

Por fim, a correlação da porcentagem de linfócitos observou-se uma discrepância entre as técnicas de citocentrifugação e citometria de fluxo. A técnica da citocentrifugação com a CCS foi negativa e significativa, todavia a citometria de fluxo apresentou relação positiva e significativa, corroborando com a informação anterior em que a porcentagem de linfócitos foi maior pela citometria de fluxo que a citocentrifugação.

\section{DISCUSSÃO}

As técnicas comparadas, neste estudo, são as mais usuais com intuito de diferenciar as distintas populações leucocitárias e diagnosticar a mastite bovina. A contagem microscópica diferencial por esfregaços diretos permite apenas a diferenciação entre MN e PMN. A citocentrifugação apresenta como ponto importante, a capacidade de diferenciar as distintas populações leucocitárias (neutrófilos, eosinófilos, basófilos, macrófagos e linfócitos) presentes no leite. A citometria de fluxo, por outro lado, além de apresentar a vantagem de diferenciar as distintas populações leucocitárias por anticorpos monoclonais específicos, não depende da subjetividade do examinador.

Por exemplo, no que concerne a maior porcentagem de macrófagos obtidos pela técnica de centrifugação em comparação a citometria de fluxo, pode ser explicado pela subjetividade da contagem da primeira. Desta maneira, além da dificuldade na análise dessa técnica ainda há o fator da subjetividade de leitura de um indivíduo a outro, especialmente ao considerar que a presença de linfócitos gigantes em bovinos pode ser confundida com macrófagos, principalmente no leite, durante a leitura (Sirois 2017).

A CCS do leite serve como parâmetro para diagnosticar a mastite bovina dado que quando há inflamação da glândula mamária o número de células somáticas se eleva, em sua maioria, PMN oriundos do sangue (Souza et al. 2012). Similarmente ao presente estudo, Dosogne et al. (2003) e Mira et al. (2013) obtiveram correlação positiva entre a porcentagem de neutrófilos com a avaliação da contagem diferencial de leucócitos pela técnica de citocentrifugação e pela citometria de fluxo, utilizando amostras de leite com baixa CCS. No entanto, a partir dos dados apresentados no Quadro 1, pode ser evidenciado que a técnica mais adequada e que aponta melhor correlação (r) com a CCS automática foi a citometria de fluxo, seguida pela centrifugação e por fim, a contagem diferencial de leucócitos por esfregaços diretos. Seguindo esse silogismo, há uma mensuração mais fidedigna pela citometria de fluxo visto que essa técnica permite a utilização de anticorpos monoclonais específicas para identificação de neutrófilos, linfócitos e macrófagos, não existindo o erro de subjetividade como foi explicado anteriormente. Deve-se salientar, no entanto, que as células epiteliais mamárias são contabilizadas na CCS automática, assim como na estratégia utilizada na citometria de fluxo no presente estudo, o que pode explicar a discreta maior correlação (r) obtida (Mira et al. 2013). Em contraste, as técnicas da contagem diferencial de leucócitos pela citocentrifugação e contagem microscópica direta por esfregaços não contabilizam essas células.
Na glândula mamaria sadia, não há um consenso na literatura, sobre a população leucocitária predominante. Por exemplo, Rivas et al. (2001), Dosogne et al. (2003) e Schwarz et al. (2011) consideram os linfócitos, a população predominante na glândula mamária sadia, porém não utilizaram anticorpos monoclonais específicos para identificar as distintas populações leucocitárias. Refutando essa afirmação, Leitner et al. (2000) e Leitner et al. (2003) acreditam que células epiteliais são as que predominam. Há ainda, mais uma corrente que apoia a assertiva de que os macrófagos são a principal população no leite oriunda de glândulas mamárias sadias, avaliadas pela microscopia (Lee et al. 1980, Miller et al. 1991, Sarikaya et al. 2004, 2005, Merle et al. 2007) e citometria de fluxo (Koess \& Hamann 2008, Blagitz et al. 2015). Considerando os resultados da citometria de fluxo, o presente estudo corrobora a mesma linha teórica do último supracitado. 0 predomínio de macrófagos no leite da cisterna da glândula mamária, próximo ao canal do teto e consequentemente a porta de entrada de patógenos na glândula mamária, enfatiza a importância desta população leucocitária na defesa da glândula mamária contra patógenos invasores (Sarikaya et al. 2005).

A identificação das populações leucocitárias no leite pela citometria de fluxo com base apenas em suas características de tamanho e granulosidade não são satisfatórias e nem apresentam alta repetibilidade (Koess \& Hamann 2008), e, portanto, apresenta limitações sem a utilização de anticorpos monoclonais específicos para identificação de cada população leucocitária. Deve-se salientar que diferentemente dos demais trabalhos (Pillai et al. 2001, Rivas et al. 2001, Dosogne et al. 2003, Koess \& Hamann 2008, Pilla et al. 2013) que avaliaram as diferentes populações leucocitárias no leite por citometria de fluxo, o presente estudo identificou a população de PMN utilizando anticorpo monoclonal específico (CH138A), não sendo identificado apenas pelas características de tamanho e granulosidade e/ou anticorpos monoclonais não específicos (p. ex. CD11b). Além disto, apesar do anticorpo monoclonal CD14 ser utilizado para identificar os macrófagos e monócitos, os neutrófilos também podem expressar CD14 no leite (Blagitz et al. 2015), assim os macrófagos e monócitos no leite foram identificados baseada na utilização dos anticorpos monoclonais CD14 e CH138, sendo positivo para CD14, e negativo para $\mathrm{CH} 138$, excluindo portanto, a identificação errônea da população de neutrófilos que expressam a molécula CD14 como macrófagos.

\section{CONCLUSÕES}

A partir dos resultados, o presente estudo reforça a ideia que os macrófagos são a população predominante no leite oriundo do úbere sadio.

Além disso, variações entre as diferentes técnicas foram encontradas, o que pode ser devido à subjetividade do examinador na contagem diferencial de leucócitos pelas técnicas de citocentrifugação e contagem microscópica direta por esfregaços, especialmente ao considerar a similaridade na morfologia entre linfócitos e macrófagos no leite, o que pode acometer erros de leitura.

A citometria de fluxo foi a técnica que apresentou a correlação discretamente mais forte com a CCS automática, evidenciando que pode ser uma ferramenta útil no diagnóstico e controle da mastite, especialmente ao considerar que não 
é influenciada pela subjetividade do examinador e avalia um número expressivo de células em um curto espaço de tempo.

Agradecimentos.- Os autores agradecem à Fundação de Amparo à Pesquisa do Estado de São Paulo - FAPESP (Project no 2009/50672-0) pelo apoio financeiro. Os autores agradecem ao Conselho Nacional de Desenvolvimento Científico e Tecnológico (CNPq) e à FAPESP pelas bolsas concedidas a AMMPDL e FNS, respectivamente.

\section{REFERÊNCIAS}

Abbas A.K., Lichtman A.H.H. \& Pillai S. 2012. Cellular and Molecular Immunology. 7th ed. W.B. Saunders, Philadelphia. 560p.

Blagitz M.G., Benites N.R., Batista C.F., Souza F.N., Dias R.A., Gomes V. \& Libera A.M.M.P.D. 2013a. Variações metodológicas na contagem de células somáticas do leite de ovelhas da raça Santa Inês. Ciência Rural 43(4):668-671. http:// dx.doi.org/10.1590/S0103-84782013000400016.

Blagitz M.G., Souza F.N., Santos B.P., Batista C.F., Parra A.C., Azevedo L.F., Melville P.A., Benites N.R. \& Della Libera A.M. 2013b. Function of milk polymorphonuclear neutrophil leukocytes in bovine mammary glands infected with Corynebacterium bovis. J. Dairy Sci. 96(6):3750-3757. http:// dx.doi.org/10.3168/jds.2012-6370. PMid:23608489.

Blagitz M.G., Souza F.N., Batista C.F., Azevedo L.F.F., Benites N.R., Melville P.A., Diniz S.A., Silva M.X., Haddad J.P.A., Heinnemann M.B., Cerqueira M.M.O.P. \& Della Libera A.M.M.P. 2015. The neutrophil function and lymphocyte profile of milk from bovine mammary glands infected with Streptococcus dysgalactiae. J. Dairy Res. 82(4):460-469. http://dx.doi.org/10.1017/ S0022029915000308. PMid:26119656.

Della Libera A.M.M.P., Araújo W.P., Kitamura S.S., Rosenfeld A.M.F. \& Birge E.H. 2004. Citologia do leite de búfalas (Bubalus bubalis) hígidas criadas no Estado de São Paulo, Brasil. Ciência Rural 34(4):1087-1092. http://dx.doi. org/10.1590/S0103-84782004000400019.

Della Libera A.M.M.P., Souza F.N., Blagitz M.G. \& Batista C.F. 2011. Avaliação de indicadores inflamatórios no diagnóstico da mastite. Arqs Inst. Biológico, São Paulo, 78:297-300.

Dosogne H., Vangroenweghe F., Mehrzad J., Massart-Leën A.M. \& Burvenich C. 2003. Differential leukocyte count method for bovine low somatic cell count milk. J. Dairy Sci. 86(3):828-834. http://dx.doi.org/10.3168/jds S0022-0302(03)73665-0. PMid:12703619.

Dulin A.M., Paape M.J. \& Weinland B.T. 1982. Cytospin centrifuge in differential counts of milk somatic cells. J. Dairy Sci. 65(7):1247-1251. http://dx.doi. org/10.3168/jds.S0022-0302(82)82337-0. PMid:7050194.

Hogeveen H., Huijps K. \& Lam T.J.G.M. 2011. Economic aspects of mastitis: new developments. N.Z. Vet. J. 59(1):16-23. http://dx.doi.org/10.1080/004801 69.2011.547165. PMid:21328153.

IDF 1971. A Monograph on Bovine Mastitis. International Dairy Federation Bulletin, Bruxelas. 85p.

Koess C. \& Hamann J. 2008. Detection of mastitis in the bovine mammary gland by flow cytometry at early stages. J. Dairy Res. 75(2):225-232. http://dx.doi. org/10.1017/S0022029908003245. PMid:18474141.

Lee C.S., Wooding F.B. \& Kemp P. 1980. Identification, properties, and differential counts of cell populations using electron microscopy of dry cows secretion, colostrum and milk from normal cows. J. Dairy Res. 47(1):39-50. http:// dx.doi.org/10.1017/S0022029900020860. PMid:7372886.

Leitner G., Eligulashvily R., Krifucks O., Perl S. \& Saran A. 2003. Immune cell differentiation in mammary gland tissues and milk of cows chronically infected with Staphylococcus aureus. J. Vet. Med. B., Infect. Dis. Vet. Publ. Hlth 50(1):45-52. http://dx.doi.org/10.1046/j.1439-0450.2003.00602.x. PMid:12710501.

Leitner G., Shoshani E., Krifucks O., Chaffer M. \& Saran A. 2000. Milk leucocyte population patterns in bovine udder infection of different aetiology. J. Vet. Med. B, Infect. Dis. Vet. Public Health 47(8):581-589. http://dx.doi org/10.1046/j.1439-0450.2000.00388.x. PMid:11075546.
Merle R., Schröder A. \& Hamann J. 2007. Cell function in bovine mammary gland: a preliminary study on the interdependence of healthy and infected udder quarters. J. Dairy Res. 74(2):174-179. http://dx.doi.org/10.1017/ S002202990600238X. PMid:17227597.

Miller R.H., Paape M.J. \& Fulton L.A. 1991. Variation in milk somatic cells of heifers at first calving. J. Dairy Sci. 74(11):3782-3790. http://dx.doi. org/10.3168/jds.S0022-0302(91)78570-6. PMid:1757620.

Mira C.S., Della Libera A.M.M.P., Souza F.N. \& Blagitz M.G. 2013. Correlação entre a contagem automática de células somáticas e a porcentagem de neutrófilos pela citometria de fluxo e pela técnica de citocentrifugação. Arq. Bras. Med. Vet. Zootec. 65(5):1403-1408. http://dx.doi.org/10.1590/ S0102-09352013000500019.

Pilla R., Malvisi M., Snel G.G., Schwarz D., König S., Czerny C.P. \& Piccinini R. 2013. Differential cell count as an alternative method to diagnose dairy cow mastitis. J. Dairy Sci. 96(3):1653-1660. http://dx.doi.org/10.3168/ jds.2012-6298. PMid:23332851.

Pillai S.R., Kunze E., Sordillo L.M. \& Jayarao B.M. 2001. Application of differential inflammatory cell count as a tool to monitor udder health. J. Dairy Sci. 84(6):1413-1420. http://dx.doi.org/10.3168/jds.S0022-0302(01)70173-7. PMid:11417700.

Prescott S.C. \& Breed R.S. 1910. The determination of number of body cells in milk by a direct method. Am. J. Public Hyg. 20(3):663-664. PMid:19599514.

Rivas A.L., Quimby F.W., Blue J. \& Coksaygan O. 2001. Longitudinal evaluation of bovine mammary gland health status by somatic cell counting, flow cytometry, and cytology. J. Vet. Diagn. Invest. 13(5):399-407. http://dx.doi. org/10.1177/104063870101300506. PMid:11580061.

Sampaio I.B.M. 2010. Estatística Aplicada à Experimentação Animal. Fundação de Ensino e Pesquisa em Medicina Veterinária e Zootecnia, Belo Horizonte. 264p.

Sarikaya H., Prgomet C., Pfaffl M.W. \& Bruckmaier R.M. 2004. Differetiation of leukocytes in bovine milk. Milchwissenschaft 59:586-589.

Sarikaya H., Werner-Misof C., Atzkern M. \& Bruckmaier R.M. 2005. Distribution of leucocyte populations, and milk composition, in milk fractions of healthy quarters in dairy cows. J. Dairy Res. 72(4):486-492. http://dx.doi.org/10.1017/ S0022029905001317. PMid:16223466.

Schukken Y.H., González R.N., Tikofsky L.L., Schulte H.F., Santisteban C.G., Welcome F.L., Bennett G.J., Zurakowski M.J. \& Zadoks R.N. 2009. CNS mastitis: nothing to worry about? Vet. Microbiol. 134(1/2):9-14. http://dx.doi.org/10.1016/j. vetmic.2008.09.014. PMid:18842362.

Schukken Y.H., Wilson D.J., Welcome F., Garrison-Tikofsky L. \& Gonzalez R.N. 2003. Monitoring udder health and milk quality using somatic cell counts. Vet. Res. 34(5):579-596. http://dx.doi.org/10.1051/vetres:2003028. PMid:14556696.

Schwarz D., Diesterbeck U.S., König S., Brügemann K., Schlez K., Zschöck M., Wolter W. \& Czerny C.P. 2011. Flow cytometric differential cell counts in milk for the evaluation of inflammatory reactions in clinically healthy and subclinically infected bovine mammary glands. J. Dairy Sci. 94(10):50335044. http://dx.doi.org/10.3168/jds.2011-4348. PMid:21943754.

Sirois M. 2017. Principles and Practice of Veterinary Technology. 4th ed. Elsevier, St Louis. 896p.

Souza F.N., Cunha A.F., Rosa D.L.S.O., Brito M.A.V., Guimarães A.S., Mendonça L.C., Souza G.N., Lage A.P., Blagitz M.G., Libera A.M.M.P.D., Heinemann M.B. \& Cerqueira M.M.O.P. 2016. Somatic cell count and mastitis pathogen detection in composite and single or duplicate quarter milk samples. Pesq. Vet. Bras. 36(9):811-818. http://dx.doi.org/10.1590/s0100-736x2016000900004.

Souza F.N., Sanchez E.M.R., Heinemann M.B., Gidlund M.A., Reis L.C., Blagitz M.G., Della Libera A.M.M.P. \& Cerqueira M.M.O.P. 2012. The innate immunity in bovine mastitis: the role of pattern, recognition receptors. Am. J. Immunol. 8(4):166-178. http://dx.doi.org/10.3844/ajisp.2012.166.178.

Walker J.B., Rajala-Schultz P.J., Walker W.L., Mathews J.L., Gebreyes W.A. \& DeGraves F.J. 2011. Variation in daily shedding patterns of Staphylococcus aureus in naturally occurring intramammary infections. J. Vet. Diagn. Invest. 23(6):1114-1122. http://dx.doi.org/10.1177/1040638711425587. PMid:22362791. 